\title{
Al césar lo que es del césar. El conflicto entre Iglesia y Estado en la California dominicana
}

\author{
Francisco Altable \\ Universidad Autónoma de Baja California Sur \\ fiaf70@hotmail.com
}

\begin{abstract}
Resumen
El conflicto de poder entre Iglesia y Estado es antiguo, multifacético y sujeto a la circunstancialidad temporal y espacial. De ahí la pertinencia de estudiar casos particulares en los que se hace concretamente manifiesto el conflicto, como el de las tensas relaciones entre los misioneros dominicos y las autoridades reales en la península de California durante las últimas décadas del siglo XVIII. El artículo aborda dicho estado de conflictividad desde el punto de vista del dilema central en las relaciones de la Iglesia con el Estado: ¿dónde radica la autoridad mayor y hasta qué punto puede la Iglesia participar del gobierno político, así como el gobierno político de la administración eclesial?
\end{abstract}

Palabras clave: Iglesia; Estado; conflicto; California; dominicos.

\section{Render unto Caesar that which is Caesar's: The Conflict between Church and State in Dominican California}

\begin{abstract}
The longstanding power struggle between Church and State is multifaceted and dependent on time and spatial circumstances. It is therefore pertinent to study specific cases of the conflict, such as the tense relationship between Dominican missionaries and the royal authorities in the Californian peninsula during the last decades of the 18th century. The article addresses this struggle from the perspective of the central dilemma of the relationship of Church and State: Who holds the highest authority and to what extent can the Church participate in political governance, and political government in ecclesiastical administration?
\end{abstract}

Key words: Church; State; conflict; California; dominicans. 


\title{
Al césar lo que es del césar. El conflicto entre Iglesia y Estado en la California dominicana
}

\author{
Francisco Altable
}

INTRODUCCIÓN

$\mathrm{E}$ 1 longevo desencuentro entre la Iglesia y el Estado sigue siendo un proceso por demás complejo, diverso en su desenvolvimiento espacial y temporal; por consiguiente, difícil de abordar en todas sus partes de una sola vez. El estudio que tiene el lector en sus manos intenta mostrar una de las tantas caras del problema en un lugar y tiempo específicos: el tiempo de la Antigua California borbónica, que también fue el tiempo de los conflictos de interés entre la orden de Santo Domingo y las autoridades civiles de aquella remota frontera novohispana.

Es este, pues, un asunto que nos remite a un debate de antiquísima memoria, pero también de visible actualidad. Cómo no estar de acuerdo con quienes dicen que la discusión está viva porque la finalidad esencial del Estado -el bienestar de los habitantes de una nación- y el propósito máximo de la Iglesia -la salvación de las almas- sigue siendo, hoy como ayer, la piedra angular que los une en el tiempo histórico. Justamente ha sido esta historicidad compartida la que explica sus alianzas y rupturas, los cambios y las continuidades en sus relaciones desde la Roma de Constantino $-\mathrm{O}$ antes, si se quiere- hasta nuestros días. Algo parecido ha escrito Antonio María Rouco Varela, pues afirma que "las relaciones de la Iglesia con el Estado - o del Estado con la Iglesia- pertenecen, por su propia naturaleza, a un orden de realidades permanentes que trascienden los límites del espacio y del tiempo porque tienen que ver con aspectos esenciales de la persona humana" (Rouco, 2008).

Durante dos milenios la celebérrima frase atribuida a Jesús de Nazaret: "dad al césar lo del césar y a Dios lo de Dios” (San Mateo 22: 15-21), lejos de convertirse en un axioma definitorio de los límites jurisdiccionales entre poder temporal y poder espiritual, devino causa de múltiples controversias, incluso entre los doctos y exégetas del Nuevo Testamento (Jedin, 1978, pp. 5-268). Muchas han sido las cuestiones que se han sucedido durante el proceso de este forcejeo milenario, pero aquí sólo se atenderán las que están directamente conectadas con los protagonistas del presente trabajo, es decir, los evangelizadores de la orden de Santo Domingo de la provincia de Santiago de México y los gobernantes civiles de la Antigua California, a saber: ¿quién llevaba el timón de la acción política, la monarquía o la Providencia?; ¿estaba la Iglesia por encima de los gobiernos civiles?; ¿debía

\section{(1)(1)}


aquella compartir con estos la potestad política o sujetarse al Estado en los asuntos de la transitoriedad?; si clérigos y mandatarios civiles habían de participar de consuno en la conducción de las sociedades humanas, ¿dónde debían situarse las fronteras de las respectivas jurisdicciones?

Los predicadores de santo Domingo llegaron a Nueva España cuando esta apenas echaba sus primeros tallos, y se les atribuye la creación del sistema misional para la cristianización de los nativos americanos (Romero, 1971). Como bien se sabe, la orden fue fundada por Domingo de Guzmán Garcés en la villa francesa de Toulouse y confirmada por el papa Honorio III en 1216 mediante la bula Religiosam Vitam. Su fundador, de cuna castellana, humanista y apasionado estudioso de la teología cristiana, sería canonizado por Gregorio IX en 1234, trece años después de que, enfermo y viejo a sus 51 años, muriera en la población italiana de Bolonia. Por ese tiempo la orden se componía de aproximadamente 300 frailes, pero este número habría de crecer en los años y centurias siguientes, consagrados a lo que el santo había señalado en vida como fin fundamental de su instituto, plasmado para siempre en el lema laudare, benedicere, praedicare, es decir, "celebrar la palabra de Dios, invocar a favor de los pecadores la bondad divina y propagar la fe católica entre los infieles e idólatras".

Como los jesuitas siglos más tarde, la orden de los mendicantes dominicos nació de la oposición a una amenaza anticatólica, la del llamado catarismo, término que es una derivación de la palabra cátaro, que significa hereje y adorador del diablo, según la tradición cristiana. Esta secta se propagó a partir del siglo x y en el XII ya representaba una fuerza temible para la Iglesia romana. Los cátaros difundían la idea de que Dios y Satanás constituían la dualidad que había creado el universo, y que la única salvación real era entregarse al ascetismo, pues la humanidad, advertían, era obra exclusiva del demonio, y sólo Dios podía rescatar a los hombres de la materialidad y transportarlos a la dicha eterna mediante la negación de los placeres sensuales. Su influencia fue pertinaz, pero ya para principios del siglo XIV operaban en la clandestinidad y se acercaban a la extinción. Sin embargo, el triunfo del catolicismo no dio paso a la supresión de la institución dominicana; por el contrario, continuó fortaleciéndose, más todavía cuando sobrevino el encuentro de Castilla con los pueblos mesoamericanos, ya que muy pronto, casi tan pronto como se consumó la conquista de los mexicas, los padres predicadores entraron al naciente reino indiano con la consigna de salvar las almas "endemoniadas" de los nativos.

Con el respaldo del encumbrado Hernán Cortés y la venia de Carlos I de España, fray Tomás Ortiz, dominico del convento salamantino de San Esteban, a la cabeza de un grupo de padres solicitantes, dio los primeros pasos hacia la autorización formal para que la orden enviara misioneros a las Indias novohispanas. Esto ocurrió al amparo de una cédula real que el monarca signó el 12 de enero de 1526. Pocas semanas después partieron de Sanlúcar de Barrameda los primeros evangelizadores de santo Domingo. Eran ocho clérigos: el padre Ortiz, como vicario, cuatro sacerdotes del convento de San Esteban, otro fraile español de procedencia desconocida, un diácono y un hermano lego. En las Antillas se les unieron otros cuatro mendicantes. En suma, fueron doce los religiosos que desembarcaron en Vera- 
cruz el 24 de junio y entraron a la ciudad de México el 25 de julio de aquel mismo 1526. Por esas tiernas fechas fue también que se fundó el prestigioso convento de Santo Domingo, austero en sus principios y presidido por uno de los recién llegados, el leonés fray Domingo de Betanzos (Fernández, 1994, pp. 43-136).

El segundo grupo de misioneros llegó al reino novohispano en 1528 , y ya desde entonces se distinguieron los dominicos por ser críticos tenaces de los métodos utilizados en las conquistas españolas. Señalaron duramente a Nuño Beltrán de Guzmán tras la sangrienta fundación de Nueva Galicia (hoy Zacatecas, Jalisco, Nayarit y Colima). Entonces y después la orden dio curso a suplicantes representaciones para que la corona variara su actitud y dejara de justificar la invasión y la esclavización de los indios por medio del trabajo obligatorio e impago -la encomienda-, lo que se consiguió a medias con las llamadas Leyes Nuevas de 1542, que no acabaron con las injusticias, pero, a la larga, limitaron el poder y los privilegios hereditarios de los encomenderos.

No admite duda que el dominico de mayor trascendencia en la historiografía novohispana fue fray Bartolomé de las Casas. Sevillano de nacimiento, jurista de profesión y latinoparlante, es considerado como uno de los fundadores del moderno derecho internacional y defensor por antonomasia de la humanidad de los aborígenes americanos, lucha que no libró solo, pues hubo otros predicadores que se hicieron oír en la corte castellana con el fin de proteger los intereses de las misiones dominicanas y los de sus neófitos, entre otros, Pedro de Córdoba, Antonio Valdivieso, Tomás de Toro y Antonio Montesinos (Fernández, 1994, pp. 53-64).
En 1530 los dominicos de Nueva España quedaron jurisdiccionalmente sujetos a la provincia de Santa Cruz de Indias, que abarcaba al conjunto de las islas antillanas pertenecientes a la corona de Castilla. En cuanto se enteraron aquellos, el disgusto cundió y casi de inmediato solicitaron la revocación de dicha providencia y la creación de una nueva jurisdicción provincial en suelo novohispano. Para mayor eficacia, fray Domingo Betanzos viajó a la metrópoli y se presentó ante el emperador mismo para hacer la mencionada súplica, que corrió con buena estrella, pues en 1533 quedó autorizada la erección de la que fue bautizada con el nombre de provincia de Santiago de México, semillero de numerosos evangelizadores. Precisamente de ella saldrían los que, 240 años después, se ocuparían de las misiones bajacalifornianas.

Hacia 1528 los dominicos misionaban en la altiplanicie nahua, pero durante el siglo XVI la presencia de la orden se extendió hasta territorios tan cercanos como distantes entre sí: Oaxaca, Chiapas, Guatemala, El Salvador, Panamá, Venezuela, Colombia, Perú y las Filipinas. A la muerte de fray Domingo Betanzos ya había sendos conventos mayores en la ciudad de México, Puebla y Oaxaca, dos menores en Veracruz y otros dos en Chiapas y Guatemala. Las fundaciones dominicanas continuaron y ello condujo a la división jurisdiccional de la provincia de Santiago en cuatro nuevas entidades: la misma de Santiago de México, la de San Vicente de Chiapas y Guatemala en 1551, la de San Hipólito Mártir de Oaxaca hacia 1596 y la de Puebla de los Ángeles en 1656 (Nieser, 1998, pp. 60-64).

Los dominicos ya tenían planes de entrar al septentrión novohispano desde

\section{(1)(1) $\circledast$}


1596, pero su realización se retrasaría por décadas, dado que, aunque fundaron el convento de Santa Cruz de Zacatecas en 1604, el propósito de expandir sus misiones tuvo que esperar largo tiempo, según se sabe, a causa de la rebeldía indígena. En 1686, año en que la resistencia amainó, establecieron seis pueblos de cristianización en la Sierra Gorda, sólo que tales asentamientos se hicieron al sureste de Zacatecas (noroeste del actual estado de Querétaro), lo que parece opuesto a la pretensión de avanzar hacia el norte. En 1700 se desataron nuevos levantamientos y otra vez se postergaron las labores de evangelización. Tras una larga espera de cuatro decenios, la pacificación de la Sierra Gorda se consiguió y entonces pudieron volver los misioneros a sus comunidades serranas. Medio siglo más tarde pasarían estas al clero secular (Nieser, 1998, pp. 66-67). Habida cuenta de lo dicho, la orden se mantuvo lejos de los territorios más norteños de Nueva España hasta su arribo a la península de California en 1772, o sea, 168 años después de que se erigiera el convento zacatecano, aunque los trámites comenzaron en 1768 con la solicitud expresa que hiciera a Carlos III el procurador general de la provincia de Santiago de México, fray Juan Pedro de Iriarte (Meigs, 1994, pp. 33-51).

El consentimiento del rey fue cosa relativamente fácil, pero el cumplimiento de la correspondiente cédula real encontró algunos escollos en la oposición de ciertos personajes e institutos poderosos, señaladamente, el renombrado visitador José de Gálvez y el colegio franciscano de San Fernando de México, cuyos religiosos administraban las misiones californianas desde que los jesuitas, sus fundadores, tuvieron que abandonarlas al ser expulsa- dos de todos los dominios españoles en 1767. Una vez vencidos los obstáculos, las Californias se repartieron por mitad entre fernandinos y santiaguinos, según quedó formalizado en un documento de convención que signaron los superiores de ambas órdenes el 7 de abril de 1772 (Del Río, 2007, pp. 189-200). En octubre de ese año desembarcó una parte de los dominicos designados en Loreto, la diminuta capital de la Antigua California. El resto lo haría en mayo de 1773.

Tanto franciscanos como dominicos trabajaron en circunstancias distintas a las de los padres de la Compañía de Jesús, que tutelaron a los nativos de la región bajo un régimen de excepción que les permitió manejar los asuntos de la provincia con bastante autonomía durante los 71 años que estuvieron en ella. Los sustitutos, en cambio, se desempeñaron a lado de una estructura político-administrativa (la Gobernación de las Californias), que había sido instalada por el propio visitador José de Gálvez. Diré de una vez que se trataba de una organización destinada a cuidar de cerca los intereses de la monarquía en el alto Pacífico novohispano, y fue precisamente la concurrencia de ambos intereses, el misional y el monárquico, lo que provocó los ásperos roces institucionales en esa parte del imperio español.

\section{El LeNGUaje De Las DOS espadas}

La teoría de las dos espadas del papa Gelasio I tiene su origen en el antiguo debate que opuso a la concepción pagana de un solo mundo habitado por seres humanos y divinidades, la inferencia judeocristiana de que había dos dimensiones dentro de la creación universal: una terrenal, resi-

\section{(1)(1)}


dencia transitoria de la humanidad, y otra celestial, eterna y perfecta. Tal divergencia fue considerada como radical desde el punto de vista del Estado politeísta, entre otras cosas porque planteaba la coexistencia de un "poder menor" -el del emperador romano-, finito y subyugado a un ser todopoderoso que gobernaba cielo y tierra. El edicto de Milán, signado por Constantino I y Licinio en 313, afinó el tono discordante de los siglos II y III aclarando que se trataba de dos potestades complementarias: Eusebio de Cesarea, en un acto de calculada conciliación con el régimen, dio impulso a la idea de que era Dios quien otorgaba un "poder divino" al soberano de Roma, a fin de que este cumpliera con la función trascendental de auspiciar los altos propósitos de la predicación cristiana. Así se fortaleció el concepto unitario de los dos reinos o ciudades, como años después lo expondría san Agustín en su Ciudad de Dios.

Pero la creencia en esta suerte de relación "simbiótica", así como ha perdurado a través de centurias y centurias, también ha sido sistemáticamente cuestionada desde la alta Edad Media. Con los triunfos del expansionismo carolingio tomó fuerza la concepción de que la autoridad política, sin negar la omnipotencia divina, antes por mandamiento suyo, tenía en sus manos la vicaría católica y el señorío sobre todos los hombres. El cesaropapismo -término acuñado por el jurista Justus $H$. Boehmer en el siglo XVII- cobró vida en la figura de Carlomagno y enfatizó la preeminencia política y religiosa en una sola persona, en tanto que el pontífice conservaba la autoridad simbólica que le daba el acto de coronar al soberano franco. Es oportuno anotar que el emperador franco mantuvo un trato de respeto y colabora- ción con el papado, pero otros futuros monarcas del Sacro Imperio RomanoGermánico -como Enrique III, Federico I y Federico II- defendieron con fiereza la supremacía de la corona imperial sobre la silla papal.

Durante el bajo medievo la Iglesia no sólo mantuvo una actitud defensiva, sino que reaccionó con determinación en contra del cesaropapismo, como cuando Bonifacio VIII publicó en 1302 la radical bula que establecía la superioridad de la Iglesia, dejando al Estado en un segundo plano, algo así como el "brazo secular" de la institución eclesial. Por cierto, Marsilio de Padua rechazó de plano el papismo bonifaciano y fue condenado por decir que el Estado era obra de los hombres y que, en lo terrenal, era la Iglesia la que debía subordinarse al poder de los príncipes.

La controversia se extendió más allá del periodo renacentista en torno a la misma cuestión: ¿la potestad terrena debía estar en manos del rey o debía este compartirla con el papa?; ¿cómo debía operar el Estado, por encima o por debajo de la curia romana? Las respuestas que se dieron en los siglos XVI y XVII quedaron lejos de ser unánimes: frente a voces como las de Nicolás Maquiavelo, Juan Calvino, Jean Bodin, Roberto Bellarmino, Francisco Suárez, John Locke y Jacques Benigno Bossuet, que concurrían en la doctrina de las dos espadas, esto es, en el respeto mutuo entre el Estado y los poderes terrenales de la Iglesia, hubo otras que, en grados distintos, abogaron por el sometimiento temporal del clero a la monarquía. Así pensaban, entre otros, Johannes Althaus, John Selden, Thomas Hobbes, Baruch Spinoza e incluso políticos de altos vuelos como el cardenal Richelieu. De

\section{(1)(1)}


manera más aislada, Martín Lutero se opuso a la teoría de las dos espadas y afirmó que todo estaba dentro del reino espiritual, supremo y auténtico de Dios.

El pensamiento y las tendencias políticas del siglo XVIII mantuvieron vigentes las discordancias. Los tratadistas ligados a regímenes absolutistas -como el de España- por lo general privilegiaron el dominio monárquico sobre cualesquiera otros sectores de la sociedad, mientras que los más reconocidos pensadores de la corriente ilustrada -Voltaire, Denis Diderot, el barón de Montesquieu- se inclinaron por la separación de las dos esferas de autoridad, aunque hubo grandes excepciones, como la de Jean-Jacques Rousseau, que debatía a favor de la subordinación de la Iglesia (González, 1992, pp. 340-342). La institución religiosa se hallaba a contracorriente de dichas visiones: ni en el fondo admitía su sumisión a un soberano absoluto, ni aceptaba que su única tarea en la tierra fuese la espiritual.

Se cree que en la España del siglo XVIII fue mayor la interferencia eclesial que en Francia e Inglaterra, ya en oposición al regalismo borbónico, ya en contra de quienes buscaban reducir al clero a un marginal papel de guía espiritual. Se sabe que, en efecto, la Iglesia hispánica deseaba conservar tanto su autonomía jurisdiccional como su participación preponderante dentro de la sociedad, sobre todo en materia de educación y en la "conducción moral” de los españoles; de ahí que las órdenes del clero regular -los dominicos no fueron la excepción- reaccionaran en defensa de sus antiguos privilegios y potestades de cara a los defensores de la política regalista, tendentes a la exaltación del trono y a la secularización de gobierno y sociedad, esto es, a la separación estricta de los poderes políticos y espirituales, a la existencia, pues, de una sola espada para todo tema de naturaleza mundana.

Los miembros de la corporación dominicana que misionaron en la Antigua California no dejaron de señalar a cada paso la relación histórica que, por un lado, unía a clero y monarquía en la posesión de la supremacía temporal, bien que, por el otro, en la separación de ámbitos de función delimitados. En cuatro palabras: juntos pero sin confundirse. Tal vez a nadie extrañe que los predicadores quisieran salvaguardar esta especie de paralelismo funcional que otorgaba a la Iglesia un peso de poder específico dentro de la sociedad colonial, dado que, con sus altas y sus bajas, esa había sido la tónica durante los siglos anteriores. Su dominio ideológico durante toda la Edad Media y los siglos del absolutismo moderno fue todo lo claro que pudo ser en tal sentido.

Como parte del aparato eclesial, las misiones constituían una expresión de la poderosa influencia que ejercía la Iglesia dentro del Estado español (Ayala, 1994, p. 66), un Estado que se proclamaba cristiano y cristianizador. Pero quizá sea más exacto decir que tales instituciones fueron consecuencia de la alianza entre ambos poderes para lograr sus respectivos fines: la "salvación de las almas" y la expansión económica y geopolítica, propósitos que, como contradictorios desde el punto de vista del programa misional, causaron innumerables conflictos entre las agrupaciones misioneras y los funcionarios del rey, según se verá.

La institución quizá más representativa de esta "simbiosis" española fue el Regio Patronato Indiano, nacido precisamente del acuerdo pragmático entre la corona y la Santa Sede para llevar a cabo 
la catequización de los pueblos americanos (González, 1992, pp. 342-344). Y en verdad supuso una relación "simbiótica", puesto que las dos partes obtuvieron beneficios mutuos: el emperador, por "concesión” papal, vio aumentada su capacidad de intervención en el funcionamiento de la Iglesia española, esto a cambio de sufragar los gastos de la "conquista" católica. El papa cedió jurisdicción en territorio hispánico, pero ganó la fuerza de un imperio para la "cruzada" americana. Las facultades del patrono se extendían a las autoridades que le servían en las Indias, aunque estaba mandado que las intervenciones patronales se enviasen a Madrid para su correspondiente aprobación. Tan fructífero como fue el convenio estuvo lejos de ponerse en práctica con total cordialidad, sobre todo porque la Iglesia tuvo que resistir las acometidas del rey, que persistía en su deseo de agrandar los espacios del poder real (Porras, 1980, pp. 57-100).

\section{LA NO TAN SORDA CONVICCIÓN SOBRE LA SUPREMACÍA DIVINA}

En el fondo, como desde los primeros tiempos del cristianismo, los misioneros dominicos mantenían firme la creencia de que la institución católica disponía de una autoridad mayor que la de cualquier monarca -que la de cualquier otra autoridad terrenal, habría que decir- sencillamente porque al fin de cuentas ella “representaba a Dios" en la tierra por medio de quienes la dirigían, el papa, en primer lugar, pero también los miembros menores. Tal convicción fue más o menos tolerada y más o menos impugnada por las monarquías a lo largo de tantos siglos, pero en el XVIII las nuevas condiciones que trajo la corriente ilustrada y el regalismo no fueron lo favorables que el clero hubiese deseado. Muestra de ello es lo que ocurrió en la antigua capital de las Californias a raíz de los roces que se dieron entre militares y dominicos. Tres soldados del presidio de Loreto llegaron a quejarse de que el padre predicador había advertido en misa que "todos" los cristianos tenían la "obligación” de dar "puntual cumplimiento" a los "santos mandamientos de la ley de Dios y de la santa Iglesia”, si es que no querían acabar sus días arrojados a la "lumbre eterna", y que, para demostrar la "superioridad" de la organización eclesiástica, había traído a colación "muchos textos de la Sagrada Escritura, Evangelios y santos padres", que "acomodó a su intención de ponderar las singulares autoridades de cualquier señor sacerdote para mandar en cualquier materia sobre toda clase de personas por su altísimo y santo ministerio". Los ofendidos declararon que el clérigo estaba en el entendido de que podía dictar órdenes al conjunto de la sociedad peninsular, aun cuando esto significase tratar con "desprecio y ultraje” a los empleados que tenía el rey en dicha provincia novohispana, con el mismo despotismo, dijeron, que lo hacían con los indios en las misiones.

Las deposiciones de estos sujetos no sólo forman parte del anecdotario local, detrás de ellas estaba también la sorda y general repugnancia del clero regular a aceptar la preeminencia terrena de otra que no fuese la divinidad católica, a pesar de que sus integrantes solían admitir, habrá que pensar que de dientes para afuera, su "calidad de vasallos del soberano español”, tal y como lo había enfatizado el poderoso visitador José de Gálvez durante su viaje de reformas a la península cali-

\section{()(1)}


forniana en 1768 (Palou, 1792, p. 63). La expulsión de los jesuitas, precisamente a causa de la "disimulada" defensa de las prerrogativas papales, y las virulentas críticas del funcionario andaluz en contra de los ignacianos reflejan esa contradicción intestina, pues decía el visitador que los misioneros de la Antigua California no dejaban reconocer más autoridad en la región que la que les exigía su "despotismo, deslealtad e ingratitud". Es pertinente adelantar que esta misma acusación la interpusieron luego los sucesivos gobernantes californianos en oposición a los dominicos, dirían ellos que para proteger los legítimos derechos del rey.

Conviene hacer aquí un matiz a propósito de la teoría de una sola espada así en la tierra como en el cielo. Si bien los dominicos anteponían la "ley de Dios" en sus conciencias, las fuentes enseñan que, al igual que los misioneros de otras corporaciones frailegas, los de santo Domingo eran cautelosos y siempre "concedían" la existencia de una instancia temporal con facultades soberanas, pero muchas veces lo hicieron con la intención de ningunear a los mandatarios provinciales, quienes, de inmediato, sacaban a relucir las credenciales que les concedía su calidad de "representantes reales".

Alegaban los religiosos que el rey y su virrey en Nueva España eran las "únicas" autoridades a que podían acudir los catecúmenos cuando los funcionarios del monarca cometían "injusticias", razón por la cual, "y en obediencia a los deberes cristianos", tenían que intervenir los "padres tutores" para hacer valer "las leyes divinas" ante los "más altos" arbitrios. Si se observa, no sólo es clara la insinuación de que el mandato regio debía atenderse; también se esboza la concepción de que la autoridad de los representantes reales podía ser desoída cuando, a juicio de los misioneros, se pasaba por alto la "tolerancia amorosa que la monarquía dispensaba a los pobres indios". ${ }^{1}$ De hecho, sugerían que el poder real era irrebatible siempre y cuando se sujetara a la jurisdicción "sobrehumana" de la Providencia católica, lo que era una forma diplomática de encumbrar el "tribunal de Dios" y realzar el papel de la Iglesia dentro de la sociedad.

Sobra añadir que desde ese punto de vista el poder del emperador tenía necesariamente que administrarse "en consonancia" con la norma cristiana, es decir, acatando lo que la Iglesia señalaba como el "justo proceder", toda vez que la justicia temporal eran vulnerable y sólo quien reinaba en los cielos podía jactarse de ser un juez infalible. Por eso el presidente de las misiones dominicas de la Antigua California tenía para sí que el bien público representaba el fin de toda legislación, sin lo cual, aseguraba, ni se respetaba la ley ni podía respetarse, pues lo que venía en perjuicio de la comunidad humana "no era ley, sino antiley y desorden". ${ }^{2}$ Advertía, refiriéndose a los indios, que la condenación de inocentes no podía ser más que una "vejación repugnante a la noción de justicia que a todos enseñaba el catecismo". ${ }^{3}$ Luego, era en el "juzgado de

${ }^{1}$ Representación de fray Vicente de Mora al virrey de Nueva España. Loreto, 20 de febrero de 1777. Californias. Vol. 36, exp. 5, f. 18. Archivo General de la Nación (AGN), México.

${ }^{2}$ Representación de fray Vicente de Mora al virrey de Nueva España. Loreto, 20 de febrero de 1777. Californias. Vol. 36, exp. 5, f. 22. AGN, México.

${ }^{3}$ Representación de fray Vicente de Mora al virrey de Nueva España. Loreto, 20 de febrero de 1777. Californias. Vol. 36, exp. 5, f. 28. AGN, México. 
Dios", materializado en los libros catequísticos, donde se dictaba el "sentido justo" de las leyes mundanas. En resumen, lo que denunciaban los dominicos era que el gobierno peninsular viciaba el "dictamen divino" y, por tanto, el del monarca.

Esta diferenciación entre poderes temporal e intemporal la trasladaba el fraile a la relación de ellos, los clérigos, con los encargados del gobierno, por una parte, y con Dios, por la otra. Establecía una manifiesta distinción entre la trinidad cristiana y el rey de España, una distinción de obvio carácter jerárquico en la que los misioneros obedecían a la corona en calidad de "vasallos" y al "Ser Supremo" en la humilde condición de "siervos". Como lo primero, se situaban por debajo de la realeza, pero a la altura del estamento noble, mientras que la "servidumbre espiritual" los sometía a una "dulce esclavitud". Dicho de otra forma, el dominico separaba por grado la subordinación del clero según se tratase de una u otra de las dos máximas potestades. Así pues, una espada era más larga y cortante que la otra. De ahí que el padre presidente dijera que sus hermanos no eran "sirvientes" de los mandatarios peninsulares, pero sí "siervos de Jesucristo". ${ }^{4}$

Una cuestión siempre delicada fue la de la colaboración militar en ayuda de los intereses misionales, por ejemplo, en lo concerniente a la recuperación de los catecúmenos fugitivos, pues en ello, se decía, iba de por medio la "redención de las almas". No era raro que los evangelizadores amenazaran con el castigo divino cuando dichas funciones se incumplían, pues

\footnotetext{
${ }^{4}$ Representación de fray Vicente de Mora al virrey de Nueva España. Loreto, 20 de febrero de 1777. Californias. Vol. 36, exp. 5, f. 35. AGN, México.
}

tal incumplimiento "contrariaba las voluntades de Dios y del rey". La "liberación espiritual" de los nativos, argumentaban, era "mandamiento divino y obligación" de todo soberano católico. ${ }^{5}$ He aquí de nuevo ese convencimiento de que debía acatarse todo precepto regio por cuanto era una extensión de la "misericordia divina", personificada en la labor de los predicadores, que lo eran por la consigna de su apostolado antes que por una política de Estado en materia religiosa.

Algo similar ocurría tratándose de la expansión del cristianismo por medio del establecimiento de nuevos centros de cristianización, para lo cual eran "imprescindibles" los recursos del erario real, toda vez que, sin esta "prueba palpable de la obediencia a los deseos de Dios", sentenciaban, los indios quedaban "a merced de Satanás", lo que ponía a los "omisos" -aun al rey, aunque no se le nombrase- en riesgo de ser llamados al "tribunal de Dios". 6

Desde esta perspectiva de tintes providencialistas la estatura del ministerio apostólico otorgaba a los misioneros, así lo entendían ellos, una "autoridad moral" sobre todos los creyentes, autoridad que provenía de sus virtuosos vínculos con la superioridad más allá del mundo sensible. Justo por eso es que no era gratuito el título de "venerables" que se les daba. Se decían vasallos del rey, pero se mostraban firmes al exigir el respeto a las facultades

${ }^{5}$ Representación de fray Nicolás Muñoz al comandante general de las Provincias Internas. Torreón de San Miguel de Horcasitas, 24 de noviembre de 1778. Californias. Vol. 16, exp. 12, f. 3. AGN, México.

${ }^{6}$ Representación de fray Nicolás Muñoz al comandante general de las Provincias Internas. Torreón de San Miguel de Horcasitas, 24 de noviembre de 1778. Californias. Vol. 16, exp. 12, f. 4. AGN, México.

\section{()(1) $(3$}


temporales que por "derecho celestial" reclamaban. No en vano el brazo derecho del presidente de las misiones californianas insistía en que si los frailes tenían la obligación de infundir en los indios la debida obediencia a los delegados del rey, tanto más debían estos venerar a los "ministros de Cristo Nuestro Señor". Atiéndase que no sólo el papa, sino los misioneros también, aunque fuese en un rango menor al vicariato, eran ministros de Dios, o sea, sus representantes en el mundo de los mortales.

\section{PROVIDENCIALISMO Y EFICACIA POLÍTICA}

Había una derivación de orden conceptual que se compadecía con la idea de la supremacía del poder divino en cuestiones temporales: los frailes tenían para sí que sus arduas labores en medios físicos tan hostiles como el de la península californiana no podían perdurar sino por intervención directa de la Providencia. Decía uno de los frailes que "sólo con la ayuda del Cielo” era que se había podido sobrellevar la miseria en las misiones bajacalifornianas cuando faltaban los sínodos que el rey tenía autorizados para la orden. ${ }^{8}$ Fue esta una forma de expresar que los proyectos de la corona solían dar frutos

${ }^{7}$ Representación de fray Nicolás Muñoz al comandante general de las Provincias Internas. Torreón de San Miguel de Horcasitas, 24 de noviembre de 1778. Californias. Vol. 16, exp. 12, f. 42. AGN, México.

${ }^{8}$ Miguel Hidalgo al virrey de Nueva España. Convento de Santo Domingo, 2 de agosto de 1791. Misiones. Exp. 1.22, f. 8. Instituto de Investigaciones Históricas de la Universidad Autónoma de Baja California (IIH-UABC), México. muy pobres debido a las circunstancias físicas y sociales casi irremontables en que se pretendían llevar a cabo, de modo que, si las misiones subsistían, era sobre todo gracias a la voluntad divina personificada en los evangelizadores, quienes hacían "esfuerzos sobrehumanos" para concretar los dictados providenciales. Es ciertamente repetitiva en los testimonios de la época esta tendencia fatalista de señalar que los predicadores de la Antigua California operaban "a la buena de Dios", y resulta inevitable preguntarse por qué la Providencia mantenía las misiones en ese estado de precariedad. Los dominicos argumentaban que así era por razones inescrutables para el entendimiento humano, acaso para "poner a prueba la enjundia y el fervor de los misioneros en la lucha contra el Maligno”.

Para los dominicos, como antes para los jesuitas y franciscanos, ${ }^{10}$ incluso el interés de la monarquía en la árida provincia de California no podía ser otro que el religioso, ya que, como era bien visible, el suelo peninsular resultaba tan infecundo en su mayor parte, que sólo la "piedad" del rey lo conservaba "por celo de la religión católica”, así como retenía otros territorios "inservibles". ${ }^{11}$ Tal retención,

${ }^{9}$ La Audiencia de Cuentas al gobernador Felipe Barri. México, 1775. Época Colonial. Legajo 1, documento 16. Archivo Histórico Pablo L. Martínez, La Paz, Baja California Sur, México; El gobernador Felipe Neve al comandante de las Provincias Internas. Monterrey, 4 de julio de 1780. Californias. Vol. 16, exp. 6, f. 198. AGN, México.

${ }^{10}$ Los jesuitas fundaron y administraron las misiones peninsulares de 1697 a 1768. Los franciscanos lo hicieron de este último año hasta 1773. Los dominicos a partir de entonces.

${ }^{11}$ Representación de fray Vicente de Mora al virrey de Nueva España. Loreto, 20 de febrero de 
no obstante, la consideraban sumamente apurada por la irregularidad de las ayudas reales, e "insostenible" sin la cotidiana fatiga de los "siervos de Dios". Uno de los frailes escribió una vez que los misioneros de santo Domingo se habían esmerado "tanto en lo espiritual como en lo accesorio", despojándose hasta de sus propios hábitos a fin de cubrir la desnudez de los indios, pues "para eso los había conducido Dios a la viña de la Antigua California”. ${ }^{12}$

Por tanto, los auxilios del soberano español no eran suficientes para el sostenimiento de las misiones, y por eso intervenía "la mano divina", pero esta no era dadivosa, porque serlo habría generado apatía entre quienes realizaban la "obra apostólica”. Así resolvían una contradicción obvia: ¿quién dificultaba la labor de los misioneros, Dios o el rey? La respuesta fue que ambos, pero uno por razones de "incuestionable sabiduría" y el otro por simple carencia temporal, en lo que cabía no sólo la rudeza del medio natural, sino, asimismo, la "actitud nefasta" de los representantes locales del Estado monárquico. De ahí que arguyeran que otra habría sido la suerte de las misiones si, desde un principio, la corona le hubiese concedido al instituto dominicano la administración directa del fondo confiscado a la Compañía de Jesús en $1767^{13}$ y si el gobierno provincial hubiese actuado de buena fe en su relación con los misioneros. Cómo era posible que las doctrinas de indios continua-

1777. Californias. Vol. 36, exp. 5, ff. 31-40. AGN, México.

${ }^{12}$ Informe de fray José Naranjo. Misión de Mulegé, 28 de marzo de 1783. Provincias Internas. Exp. 1.6, f. 24. IIH-UABC, México.

${ }^{13}$ Se refería al Fondo Piadoso de las Californias, fundado por el jesuita Juan María de Salvatierra. sen vivas, se preguntaban: "a la verdad, sólo milagrosamente”, se respondían. ${ }^{14}$ De esto se sigue que el clero subsanaba las ineficiencias del Estado por "gracia divina".

Esta clase de fatalismo se basaba en una convicción abstracta del desarrollo de los acontecimientos, pero también comportaba una finalidad práctica. A propósito de la primera fundación misional de la orden en la Antigua California ${ }^{15}$-hecha en un paraje que llamaron Viñadaco, aproximadamente donde hoy se asienta la población bajacaliforniana de El Rosariohacían ver los padres predicadores el "hecho indiscutible" de que hubiese sido Dios quien los guiara hasta tierras algo más "fértiles" para expandir la fe cristiana, pero que sería riesgoso precipitarse en repartir parcelas individuales entre los neófitos, como lo deseaba el soberano, pues eso podría alejarlos de la instrucción y descarriar los "santos fines" de "ambas majestades”, lo que constituía una velada defensa del sistema misional ante las arremetidas de la política secularizadora, ${ }^{16}$ de

${ }^{14}$ Representación de fray Vicente de Mora al virrey de Nueva España. Loreto, 20 de febrero de 1777. Californias. Vol. 36, exp. 5, ff. 32. AGN, México.

${ }^{15}$ Se trata de la misión de Nuestra Señora del Rosario de Viñadaco.

16 "Política secularizadora", es decir, el conjunto de medidas que tomó la monarquía española con la finalidad de suprimir las jurisdicciones misionales (a cargo del clero regular), y dar paso al régimen parroquial (parte operativa del clero secular). En un sentido más amplio, se trata de una política promotora de la construcción de la sociedad civil (secular, temporal), en este caso, en los territorios tradicionalmente ocupados por centros de evangelización, como es el caso de la Antigua California y demás provincias del septentrión novohispano. 
lo que hablaremos más adelante. ${ }^{17} \mathrm{La}$ conexión entre pragmatismo y providencialismo estaba en que, según creían, el tradicional sistema comunitario de las misiones, no su conversión en parroquias ni el fraccionamiento privado de su jurisdicción, era lo indicado para el bienestar de los indios, pues "así lo tenía dispuesto la Providencia", y si el Estado absolutista actuaba en contra de ello, el "único resultado dable" sería la ruina de los pueblos y la fuga de los catecúmenos.

La orden de Santo Domingo tenía otra preocupación respecto de las misiones bajacalifornianas, una que tiene que ver con la defensa institucional frente al Estado borbónico: ¿qué efecto nocivo tendría para los dominicos el descalabro del apostolado californiano? No se trataba de una interrogante ociosa. Tal desgracia se veía venir por la irrefrenable mortandad de los indios peninsulares a causa de las pestes intermitentes que los diezmaban desde hacía décadas. La respuesta fue necesariamente de carácter reivindicativo. En primer lugar, lo que ya se ha dicho: puesto que la realidad natural la definía en un todo la "voluntad celestial", sería la inapelable determinación de Dios el fundamento de la aridez y del consecuente derrumbe de la empresa evangelizadora. ${ }^{18}$ En cuanto al desprestigio que podría sobrevenir, se hacía énfasis en que, no obstante la "eficacia y abnegación" de los predicadores, las misiones peninsulares iban

${ }^{17}$ Representación de fray Vicente de Mora al virrey de Nueva España. Loreto, 20 de febrero de 1777. Californias. Vol. 36, exp. 5, ff. 11-12. AGN, México.

${ }^{18}$ Carta del padre Miguel Hidalgo al virrey de Nueva España. Convento de Santo Domingo, 2 de agosto de 1791. Misiones. Exp. 1.22, f. 4. IIH-UABC, México. hacia la extinción, lo cual acaso serviría a algunos "malintencionados" para introducir la "mentira" de que la negligencia o, peor, otros "fines e intereses siniestros" de los misioneros eran la fuente de semejante calamidad. ${ }^{19}$

Tanto jesuitas como franciscanos y dominicos dejaron traslucir en sus escritos esa "necesidad" de justificar su participación en la evangelización de los indios californianos y de salvaguardar a sus respectivos institutos de cualquier señalamiento que pudiera acarrearles la crítica social. Siempre que fue necesario los discípulos de santo Domingo subrayaron su más sincera disposición de contribuir a la secularización de las misiones y de bregar a brazo partido a fin de conseguir que los indios progresaran material y espiritualmente; pero se hacían estas declaraciones justamente porque la realidad les negaba el buen éxito de sus aspiraciones apostólicas en la región y sentían la necesidad de justificarse ante el poder temporal; ${ }^{20}$ aunque, como decían ellos, los "supremos tribunales" de Dios, "infinitamente equitativos", supieran de su recta y fervorosa conducta. ${ }^{21}$

Fueron insistentes en señalar que las nuevas fundaciones de hechura dominica en el norte de la península -como la mencionada de Viñadaco- acreditarían sobradamente su presencia en la provincia. La

\footnotetext{
${ }^{19}$ Informe de fray Domingo Barrera. México, 6 de septiembre de 1809. Misiones. Exp. 2.5, f. 1. IIH$\mathrm{UABC}$, México.

${ }^{20}$ Informe de fray Domingo Barrera. México, 16 de agosto de 1809. Misiones. Exp. 2.5, ff. 2-3. IIHUABC, México.

${ }^{21}$ Fray Miguel Hidalgo al virrey de Nueva España. México, 2 de agosto de 1791. Misiones. Exp. 1.22, f. 7. IIH-UABC, México.
} 
exaltación del método tradicional de evangelización, "siempre asistido por la Providencia”, fue una forma de demostrar que ellos, sobre todo ellos, eran quienes estaban allanando el camino de la colonización al norte de las antiguas misiones jesuíticas.

\section{LA DEFENSA DE LA FRONTERA JURISDICCIONAL}

Como ha quedado insinuado en los apartados anteriores, un hecho que dividió profundamente las relaciones entre el clero regular y la autoridad civil en la Antigua California fue el persistente conflicto jurisdiccional debido a las contradicciones habidas entre los intereses de la institución misional y los propios del régimen borbónico. La batalla por hacer valer su autoridad frente a la de los gobernadores y defender los recursos naturales y humanos de las misiones exhibía la inexorable discordancia entre la concepción misma de la institución religiosa sobre cómo debían ser administradas las misiones y la alta consigna que llevaban los mandatarios civiles de fomentar la secularización de la provincia por todos los medios a su alcance. Producto de ello fueron los informes en que se criticaba duramente el método de reducción en las misiones dominicas y el "deplorable" estado de los naturales. ${ }^{22}$

Decía el gobernador Felipe $\mathrm{Neve}^{23}$ que entre sus obligaciones, es decir, dentro de

${ }^{22}$ Informe del gobernador Diego de Borica. Noticia de las misiones que ocupan los religiosos de Santo Domingo. Monterrey, 29 de abril de 1799. Provincias Internas. Exp. 2.6, ff. 1-4. IIH-UABC, México.

${ }^{23}$ Felipe de Neve gobernó la provincia de las Californias de 1775 a 1782 . sus atribuciones jurisdiccionales, estaba la de promover el interés particular de los indios y el fomento económico y poblacional de la península. Quería decir que, en virtud de tales facultades, debía estar al tanto e intervenir, si fuera necesario, en el gobierno temporal de las misiones, pues estas, según el informe que rindió, estaban estrechamente ligadas a su "deber" de dar impulso al progreso material de la península (Martínez, 2005, p. 354). Los misioneros se decían extrañados de que hiciera tal aclaración y respondían que también ellos estaban preocupados por la prosperidad regional y el bienestar de los naturales. Pero precisamente ahí estaba uno de los nudos del conflicto, dado que las definiciones de "progreso" y "bienestar" diferían entre las partes.

Alegaban los religiosos que el gobernador en turno y otros mandos menores solían hacer mal uso de sus respectivas atribuciones, enderezando sus "malas artes" contra quienes administraban las misiones en beneficio de la monarquía y contrariando las ordenanzas que había dejado a su paso el visitador José de Gálvez. Un ejemplo de estos abusos, decía el superior de los predicadores, era la remoción "caprichosa" de los sirvientes y soldados asignados a los pueblos de misión destinados a mantener el orden y proteger la vida de los predicadores, ello bajo pretexto de que se hacía por "necesidades del real servicio”. Argüía que semejantes resoluciones perjudicaban las labores misionales, pues con los sirvientes y soldados removidos se removía también la vital ayuda que estos prestaban, ya en el desempeño de las actividades productivas, ya en la conservación del orden, ya para ejercer presión sobre los indios cuando estos se resistían a cultivar

\section{(1)(1) $\circledast$}


las tierras. ${ }^{24} \mathrm{El}$ gobierno provincial respondía que aquella acusación era "imprecisa y tendenciosa”; que sólo se quitaba y ponía personal cuando era "rigurosamente necesario y sin afectación considerable de las misiones ni de la seguridad de sus ministros"; que no era el gobernador quien se inmiscuía injustificadamente en la administración misional, sino los propios quejosos en los asuntos de competencia civil, ya que, así lo señalaba, se excedían al dar órdenes a los soldados como si estos fuesen "criados suyos", así como en la pretensión de reglar la custodia y defensa de los puestos. ${ }^{25}$ Los misioneros declaraban que no, que ellos ni remotamente se las daban de capitanes, bien que se reservaban una "legítima" competencia en ciertas tareas, para las cuales, decían, los soldados "carecían de conocimiento", por ejemplo, qué tierras eran cultivables o qué lugares ofrecían las mejores condiciones para la erección de misiones. ${ }^{26} \mathrm{Si}$ se observa, el fondo de la discusión no está en la "inconveniencia" de reasignar sirvientes y gente de armas, o en la supuesta incapacidad cognitiva del personal militar, sino en la disputa que protagonizaban dominicos y gobernadores en defensa de lo que cada parte consideraba su correspondiente ámbito de poder y competencia.

${ }^{24}$ Representación de fray Vicente de Mora al virrey de Nueva España. Loreto 20 de febrero de 1777. Californias. Vol. 36, exp. 5, f. 10. AGN, México.

${ }^{25}$ Representación de Felipe Neve al comandante de las Provincias Internas. Monterrey a 4 de julio de 1780. Californias. Vol. 16, exp. 6, f. 2. AGN, México.

${ }^{26}$ Representación de fray Nicolás Muñoz al comandante general de las Provincias Internas. Torreón de San Miguel de Horcasitas, 24 de noviembre de 1778. Californias. Vol. 16, exp. 12, f. 6. AGN, México.
Los dominicos fueron más allá en sus inconformidades frente a la representación provincial de la monarquía. Como ya se vio, acudieron a sus "derechos divinos" con el propósito de acusar a los soldados y marineros de la Antigua California de insistir en la "errónea" concepción de que los misioneros no tenían más facultades que las espirituales, "olvidándose de que la Iglesia, y Jesucristo mismo, les daban licencia para fungir también como guías morales de la sociedad en su conjunto", con autoridad suficiente para reprender a todos los habitantes de la península cuando las "leyes de Dios" sufriesen menoscabo. ${ }^{27}$ No pedían abiertamente que el propio gobernador y sus subordinados reconocieran la naturaleza terrenal de sus potestades; tal cosa sería un innecesario y riesgoso desafío a la autoridad del monarca absoluto, pero sí que los mandatarios provinciales se abstuvieran de meter las manos en el gobierno económico de las misiones, pues en este caso la espiritualidad dependía en mucho de la temporalidad, "tan privativamente" confiada a los padres predicadores por las más altas instancias civiles y eclesiásticas. De no ser así, las misiones estaban "condenadas al desastre”, y advertían que, si esa iba a ser la práctica, mejor sería renunciar a ellas, velada amenaza que por lo general tenía un efecto disuasivo, por lo que nunca llegó a concretarse, a pesar de que no cesaron las intervenciones de los gobernadores en los asuntos de misiones.

Aquí y allá, en sus cartas e informes, anticipaban que no habría paz en la penín-

${ }^{27}$ Representación de fray Nicolás Muñoz al comandante general de las Provincias Internas. Torreón de San Miguel de Horcasitas, 24 de noviembre de 1778. Californias. Vol. 16, exp. 12, f. 42. AGN, México. 
sula mientras el jefe político "no comprendiera” que la administración de las misiones bajacalifornianas estaba, por regia disposición, enteramente a cargo de la orden; así cumplía el rey con su "deber cristiano”, deber que se autoimponía como máxima autoridad terrena, junto con el papa, de "velar por los designios de Dios y de su Iglesia”. De esto se seguía que "salvar las almas" de los indios californianos era "cristiana" responsabilidad del monarca español, lo que encontraba su modus operandi en la labor de los evangelizadores, que no hacían otra cosa que ceñirse al "decreto divino de conservar y adelantar por todos los medios justos los bienes temporales" de los catecúmenos y de distribuir el pan entre ellos, "no por terreno interés, sino por caridad y en virtud de la confianza que el soberano tenía depositada en los predicadores". ${ }^{28}$

En sus escritos subrayaban que celar "el sustento de sus hijos" sin pedir licencia a ninguna autoridad civil no debía ser motivo de resentimiento ni constituía ningún insulto a "la jurisdicción real", antes justamente se esperaba que el misionero asistiera en todo a los indios "por el bien de sus almas”. ${ }^{29}$ El recurso argumentativo de la salvación espiritual lo llevaron no pocas veces hasta alturas ciertamente apologéticas, diciendo que su intención era emular a los "primeros apóstoles de la ley de Jesucristo”, y ser, como ellos, los más

${ }^{28}$ Representación de fray Nicolás Muñoz al comandante general de las Provincias Internas. Torreón de San Miguel de Horcasitas, 24 de noviembre de 1778. Californias. Vol. 16, exp. 12, f. 44. AGN, México.

29 Representación de fray Nicolás Muñoz al comandante general de las Provincias Internas. Torreón de San Miguel de Horcasitas, 24 de noviembre de 1778. Californias. Vol. 16, exp. 12, f. 46. AGN, México. sabios, prudentes, fieles y celosos en la distribución del socorro temporal, poderosos para proveer a los fieles el sustento necesario del cuerpo, llenos de milagrosa virtud para acudir al remedio de cuantas necesidades exigía la caridad, sin abandonar jamás la oración y la predicación de la palabra de Dios, a pesar de las murmuraciones y quejas en materia de temporalidades. ${ }^{30}$

Visto así, la jurisdicción política y militar delegada en los gobernantes de la península californiana tenía la trascendente finalidad de coadyuvar a la consecución de los fines del apostolado católico, no de "subyugar" a los evangelizadores en función de intereses temporales.

Conviene insistir en que, con todo y que se decían respetuosos de la autoridad provincial, en realidad había una buena dosis de menosprecio en la forma de entender su relación con los jefes políticos, pues no reconocían otra dependencia que la que tenían con los superiores de la orden, con el virrey de Nueva España, con el comandante general de las Provincias Internas ${ }^{31} \mathrm{y}$, desde luego, con el rey, "como las únicas [autoridades] a que debían responder", ${ }^{32}$ lo que no podía ser más despreciativo de la jurisdicción local. Y hasta

${ }^{30}$ Representación de fray Nicolás Muñoz al comandante general de las Provincias Internas. Torreón de San Miguel de Horcasitas, 24 de noviembre de 1778. Californias. Vol. 16, exp. 12, f. 52. AGN, México.

${ }^{31}$ En 1776 se formalizó el establecimiento de la Comandancia General de las Provincias Internas, en cuya jurisdicción quedaron incluidas las Californias hasta 1792.

32 Representación de fray Nicolás Muñoz al comandante general de las Provincias Internas. Torreón de San Miguel de Horcasitas, 24 de noviembre de 1778. Californias. Vol. 16, exp. 12, f. 48. AGN, México. 
quizá sea sintomático que nombrasen en primer lugar a la superioridad dominicana, pues podría ser otra forma de decir que para ellos la máxima autoridad en la península era, en realidad, la clerical. ${ }^{33}$

Por obvias razones, las diferencias se hicieron más virulentas cuando se trataba de "proteger" a los indios catecúmenos, cuyo "bienestar" dependía, según los misioneros, de que estos permanecieran a cargo de las misiones, y según los gobernadores, de su salida de ellas, puesto que estos últimos veían en el "patrocinio" misional un viejo obstáculo que cerraba el paso a la integración de aquellos a la pequeña sociedad civil de la provincia. Y, en efecto, la percepción de los frailes contrariaba la idea, muy extendida por entonces entre los funcionarios reales del régimen borbónico, de que era necesario y benéfico que los nativos cohabitasen con los españoles en asentamientos de población mixta como un medio para llevarlos a una "feliz y próspera" independencia. Remisos a toda teoría que estigmatizase al sistema misional, los dominicos se defendían enfatizando las "dañinas" consecuencias que se producían cuando, pasando por encima de las facultades jurisdiccionales de los misioneros, se les iba la mano a los justicias reales en los castigos que imponían a los indios, "causa de tantos enfrentamientos y contrario a la justicia de Dios y del rey". ${ }^{34}$ No debe

${ }^{33}$ Representación de fray Nicolás Muñoz al comandante general de las Provincias Internas. Torreón de San Miguel de Horcasitas, 24 de noviembre de 1778. Californias. Vol. 16, exp. 12, f. 49. AGN, México.

${ }^{34}$ Representación de fray Nicolás Muñoz al comandante general de las Provincias Internas. Torreón de San Miguel de Horcasitas, 24 de noviembre de 1778. Californias. Vol. 16, exp. 12, f. 41. AGN, México. extrañar que los gobernadores culparan a los frailes del mismo defecto, poniendo a la vista los "malos tratos" que recibían los nativos en las misiones.

\section{A CONTRACORRIENTE DEL ESTADO SECULARIZADOR}

En las primeras páginas de este artículo vimos cómo los impulsos secularizadores de las monarquías europeas tenían una historia de siglos al momento de la llegada de los dominicos a la Antigua California. Se conviene en que, cuando menos desde la época renacentista, el Estado monárquico fue cada vez más insistente en sus intentos de subordinar al clero. "La desdivinización de la naturaleza”, en palabras de María del Carmen Rodríguez González (1999), supuso "la concepción de un hombre libre de todo poder teológico y capaz de construir un nuevo universo", idea crucial que luego los exponentes del pensamiento ilustrado quisieron llevar a su máxima expresión.

Es de conocimiento general que los más progresistas de entre los reformadores ligados al trono español defendieron la "conveniencia" de convertir a los miembros del clero secular en una "especie de funcionarios al servicio de la política reformista" y censuraron al clero regular por sus "corruptelas", "tolerancia ante las creencias supersticiosas", métodos "desacertados" y "excesiva lealtad" al papa en asuntos que se consideraban de estricta incumbencia estatal (Rodríguez, 1999, pp. 197-203). Contra lo que consideraron infundios maquinados por los "enemigos" de la orden, los dominicos pugnaron, aunque fuese con mesura, por la defensa de la autonomía eclesial, por 
el monopolio del catolicismo en territorio español y por la supremacía eclesiástica en la educación, al tiempo que se opusieron a los avances del regalismo y de la secularización galopante, a la libertad de culto y al embrionario laicismo del siglo XVIII.

Esto explica en buena medida el grado de conflictividad que se dio entre los frailes dominicos y los poderes provinciales en la península de California durante el último cuarto del siglo XVIII, aun considerando que la reducción de los gentiles dio a los misioneros cierta capacidad de impugnación frente al régimen, algunos de cuyos representantes concebían a los pueblos misionales como instituciones que coartaban los derechos civiles de los indios. Y no se trataba de una acusación descabellada, ya que, como decía el dominico Luis Sales, cada misión era "una pequeña pero ordenada república”, en la cual el misionero lo era todo, "incluso juez", sin cuya autorización "nadie salía, ni siquiera a beber agua” (León-Portilla, 1983, p. 128). Tal vez suene algo excesivo, pero existen muchos otros testimonios que hablan de la recia autoridad que los religiosos imponían dentro de sus espacios jurisdiccionales y de cuánto los celaban.

La concepción ilustrada de que "por ley natural" los hombres nacían libres para alcanzar su bienestar económico mediante el uso de sus atributos individuales fortaleció la idea de que la pertenencia del suelo debía emanciparse de aquellas instituciones que, de uno u otro modo, obstruían los ímpetus de la "sana" ambición y los "anhelos individuales de una vida mejor".

El individualismo trajo a la política española un argumento persuasivo para la secularización de los pueblos misionales: los indios catecúmenos podrían escapar a los "perjuicios" del rancio paternalismo segregacionista, "implícito en el sistema comunitario de las misiones", para integrarse a la sociedad colonial en calidad de sujetos independientes, lo cual podía lograrse mediante la individualización del trabajo productivo en los pueblos de evangelización mediante la repartición de parcelas y ganados de posesión particular. ${ }^{35}$ Asimismo, el contacto directo con los colonos españoles sería un estímulo adicional para alcanzar la autosuficiencia de los indios durante el trayecto hacia el sistema parroquial. De ahí que las autoridades civiles de la Antigua California, con base en dicha consideración teórica, contraatacaran la renuencia de los misioneros a proveer de trabajadores indígenas a las minas y al gobierno (Bernabéu, 1992, pp. 1617). La expresión más clara de esto fue la pretensión de apresurar el tránsito de la jurisdicción misional al régimen secular, lo que precisamente se puso de manifiesto en las instrucciones que publicó José de Gálvez en la península.

Sépase que tal apresuramiento no tuvo mayores efectos prácticos por las condiciones de precariedad que acusaban los pueblos misionales y por el estado mismo de la población indígena. No obstante, el proyecto secularizador encontró otras formas de ejercer presión sobre los misioneros: las objeciones de los religiosos a que se sacasen indios de las reducciones con la finalidad de emplearlos en las obras públicas sirvieron a los mandatarios peninsulares para crear la imagen de que los dominicos eran contrarios a la integración social

${ }^{35}$ El gobernador Gaspar de Portolá al virrey de Nueva España. Loreto, 9 de abril de 1768. Californias. Vol. 76, exp. 45, f. 43. AGN, México.

\section{(1)(1)}


de los naturales, según lo dictaban "las santas y justas leyes del soberano". Y, ciertamente, el uso del trabajo indígena fue causa ordinaria de enfrentamientos, para los frailes porque se decían "protectores" de los indios ante las "injusticias" del gobierno civil, y para los gobernantes porque aquellos les "negaban" a los indios el "benéfico" contacto con la "gente de razón" y provocaban en sus tutelados "la desobediencia que debían guardar a los representantes del rey en la península". ${ }^{36}$ Obsérvese cómo la autoridad civil hace uso de la entidad divina para hacer valer sus objetivos. Así, Dios fue para unos y otros un instrumento de justificación.

Los misioneros encontraron en la aridez de la península un argumento difícil de rebatir cuando se trataba de justificar las estrecheces en las reducciones y el "atraso y desnudez" de los indios. ${ }^{37}$ Advertían que las misiones eran tan pobres que su secularización sería inútil, dado que, en algunas, la producción de aceite se limitaba a "cuatro aceitunas y una botija", ${ }^{38}$ lo que constituía una evidente exageración para poner de relieve la dificultad de convertir a los indios peninsulares en agricultores independientes. Esto, decían, era tan difícil como "juntar el cielo con la tierra", ${ }^{39}$

${ }^{36}$ El gobernador Gaspar de Portolá al virrey de Nueva España. Loreto, 9 de abril de 1768. Californias. Vol. 76, exp. 45, ff. 33-34. AGN, México.

${ }^{37}$ Representación de fray Vicente de Mora al virrey de Nueva España. Loreto, 20 de febrero de 1777. Californias. Vol. 36, exp. 5, ff. 7-8. AGN, México.

${ }^{38}$ Representación de fray Vicente de Mora al virrey de Nueva España. Loreto, 20 de febrero de 1777. Californias. Vol. 36, exp. 5, f. 8. AGN, México.

39 Representación de fray Vicente de Mora al virrey de Nueva España. Loreto, 20 de febrero de 1777. Californias. Vol. 36, exp. 5, f. 2. AGN, México. y tanto como querer "edificar en desiertos". ${ }^{40}$

Es preciso reparar en que, al lado de la concepción de un indio capaz de vivir fuera de la misión, existía otra que describía a los nativos americanos como sujetos de naturaleza "débil y cobarde". Por otra parte, los que se mostraban hostiles a la invasión eran considerados "esclavos de su idolatría y barbarie”. Especialmente entre los misioneros estaba muy difundida la idea de que los cazadores-recolectores norteamericanos eran seres que intelectualmente tardaban mucho en abandonar la "niñez". A veces esta creencia fue un recurso justificativo de la perpetuación del sistema misional; de ahí que los gobernadores de las Californias y otras autoridades novohispanas afirmaran que los religiosos deseaban tener a los catecúmenos siempre "sujetos a sus faldas", como si fuesen "infantes que no maduraban".

Informaban los dominicos que aun trabajando con el sistema de comunidad era necesario guiar a los indios en todo, lo que constituía un argumento en contra de la privatización de las tierras misionales y una muestra de que la secularización era todavía impracticable. ${ }^{41}$ Esto no podía contradecir más las pretensiones del Estado borbónico. A juicio de los gobernantes, los padres de santo Domingo rechazaban, a la sorda, la "justa idea de civilizar a los naturales de California”, ello con el fin de mantenerlos bajo su "absoluto

${ }^{40}$ Representación de fray Vicente de Mora al virrey de Nueva España. Loreto, 20 de febrero de 1777. Californias. Vol. 36, exp. 5, f. 3. AGN, México.

${ }^{41}$ Representación de fray Vicente de Mora al virrey de Nueva España. Loreto, 20 de febrero de 1777. Californias. Vol. 36, exp. 5, ff. 6-11. AGN, México. 
dominio", subyugados a un "estado de esclavitud" que no acababa después de casi 80 años de régimen misional, "y sin repartirles tierras en posesión individual para que aprendiesen a valerse por sí solos" (Bernabéu, 1992, pp.16-17).

No puede ignorarse el hecho de que el programa de cambio cultural fue en la península californiana una empresa de tintes utópicos, más aún si se piensa que el acabamiento de los indios como grupo étnicamente diferenciado tocaba ya con fuerza las puertas de los templos misionales y casas de gobierno. Que los indios dependiesen de sí mismos, tratándose de tú a tú con los colonos, sencillamente les parecía a los propios misioneros una "quimera". ${ }^{42}$ Sin embargo, contra toda obviedad, la corriente secularizante siguió su marcha, aunque a cuenta gotas, al paso que las misiones desfallecían y el número de indios caía dramáticamente.

Por otro lado, es comprensible que los dominicos refutaran las imputaciones de los jefes políticos de la provincia, y habrá que entender esto como una forma de resistencia a lo que les resultaba atentatorio de las facultades que les exigía su "irrenunciable" función redentora. Uno de ellos decía que, "como tan conforme a las leyes del rey", a ninguno de los naturales debía dárseles plazas de marineros, pues "esas contrataciones les impedían conocer bien la doctrina cristiana y, así, vivían y morían sin saber lo necesario para salvarse". 43

42 Representación de fray Vicente de Mora al virrey de Nueva España. Loreto, 20 de febrero de 1777. Californias. Vol. 36, exp. 5, ff. 6-30. AGN, México.

${ }^{43}$ Representación de fray Nicolás Muñoz al comandante general de las Provincias Internas. Torreón
Dado que el monarca y el virrey de Nueva España estaban muy lejos de la península californiana, a los predicadores les resultaba relativamente fácil maniobrar a favor de los intereses de su instituto a través de los superiores de la orden. Sabían que su presencia en tierras de gentiles era prácticamente indispensable para llevar a buen puerto los planes de la monarquía, aunque esta no dejara de presionar a través de sus funcionarios para acortar la existencia de las misiones. "Con el gobernador nos hemos portado como muertos", escribió una vez el padre presidente de los dominicos, ${ }^{44}$ y declaró que "no había nada que desearan más que dedicarse solamente a lo espiritual", culpando al gobierno de no disponer lo conducente a la secularización e informando que se alegrarían "infinitamente" si el virrey les ordenaba fraccionar las tierras misionales, cuando, a simple vista, eso era algo que en realidad deseaban hacer al ritmo de sus propósitos institucionales. ${ }^{45}$

Parece sintomático que los dominicos ensalzaran los tiempos jesuíticos como una época en la que los padres de la Compañía habían gozado de concesiones excepcionales para gobernar la península y administrar el Fondo Piadoso de las Californias sin la "incómoda" presencia de los gober-

de San Miguel de Horcasitas, 24 de noviembre de 1778. Californias. Vol. 16, exp. 12, f. 41. AGN, México.

${ }^{44}$ Representación de fray Nicolás Muñoz al comandante general de las Provincias Internas, Torreón de San Miguel de Horcasitas, 24 de noviembre de 1778. Californias. Vol. 16, exp. 12, f. 35. AGN, México.

${ }^{45}$ Representación de fray Nicolás Muñoz al comandante general de las Provincias Internas. Torreón de San Miguel de Horcasitas, 24 de noviembre de 1778. Californias. Vol. 16, exp. 12, f. 13. AGN, México.

\section{()(1) $(9$}


nadores. De ahí se desprendía que la sujeción al gobierno provincial se traducía en perjuicios no sólo para la orden, sino incluso para la política de secularización, aunque de todas formas continuamente advertían que toda actividad mundana les resultaba "repugnante" y se cuidaban de que sus comentarios sobre el pasado jesuítico se interpretaran como un acto desleal a los designios de Madrid. ${ }^{46}$

\section{CONCLUSIÓN}

Las dificultades entre misioneros y autoridades civiles en la California dominicana fueron reflejo de una problemática general mucho más antigua y compleja: la del milenario debate en torno a la autoridad temporal de la Iglesia y el Estado occidentales. El caso californiano exhibe la coexistencia de dos espacios de poder indisolublemente unidos por el carácter mismo del expansionismo español, que era, a un mismo tiempo, ambición de tierras, ambición de riqueza y ambición de almas.

Las mayores discrepancias se dieron en lo concerniente a los tiempos de la instrucción catequística, al contenido y formas de aplicación de los métodos de reducción y a las facultades jurisdiccionales para el gobierno de las misiones. Los clérigos se decían llamados a cumplir con la "obligación sagrada" de su apostolado, lo que, así lo creían, les daba "autoridad privativa y superior" sobre la forma en que "debía" realizarse la incorporación de

\footnotetext{
${ }^{46}$ Representación de fray Nicolás Muñoz al comandante general de las Provincias Internas. Torreón de San Miguel de Horcasitas, 24 de noviembre de 1778. Californias. Vol. 16, exp. 12, f. 15. AGN, México.
}

los indios californianos al conjunto de la cultura dominante, mientras que los representantes de la corona, impulsados por el intrínseco carácter integracionista de la política secularizadora, se consideraban autorizados para intervenir en los asuntos temporales de las misiones, ya que esto formaba parte medular del proyecto colonizador de la monarquía en el alto Pacífico novohispano.

Con todo y lo tirantes que llegaron a ser las relaciones entre misioneros y mandatarios, la incompatibilidad de intereses no podía ser absoluta; serlo hubiera dado al traste con los planes específicos de cada parte. Los objetivos de fondo crearon mecanismos de ajuste y convención con objeto de evitar crisis que llegaran a paralizar los avances tanto geopolíticos como religiosos. El punto de entendimiento fue el de siempre: que uno no podía triunfar sin el otro, del mismo modo que se entendía que la bienandanza de la humanidad resultaba imposible de alcanzar sin el cultivo de la espiritualidad y la ética religiosas; y también en sentido contrario: que la educación religiosa encontraba en la estructura del Estado un medio ideal para el funcionamiento de la institución eclesiástica. Es difícil de creer que los jefes políticos de la península hubiesen podido concretar el delicado tránsito entre la gentilidad y la civilización cristiana. Con la misma lógica, también parece peliagudo que el clero regular hubiera logrado sostener por sí solo la reducción de los indios sin contar con la ayuda financiera y la organización misma del Estado hispánico.

Por más que la Iglesia fuese una institución tan temporal como el Estado, su enorme influencia social, fundada en una creencia de masas que rendía fidelidad a una entidad omnipotente, cancelaba toda 
pretensión de reducirla al aparato político de cualquier nación. En todo caso, tanto la exclusión de uno como la convivencia pacífica entre ambos eran empeños utópicos desde hacía más de 2000 años. Tenían razón los dominicos de la Antigua California cuando decían que "no habría paz mientras las autoridades provinciales mantuvieran las manos dentro de las misiones", pero lo mismo podía decirse -y se decía- en sentido contrario.

La cristianización de los aborígenes de América constituye un largo periodo dentro del polifacético proceso de las a veces turbulentas relaciones entre las dos espadas, y no podía durar sino el tiempo que duró la posibilidad de contar con catecúmenos en las reducciones de indios. Era cuestión de tiempo para que las tendencias secularizadoras se impusieran y el eterno debate tomara nuevos rumbos.

\section{LISTA DE REFERENCIAS}

-Ayala Mora, E. (1994). La relación Iglesia-Estado en el Ecuador del siglo XIX. Procesos. Revista Ecuatoriana de Historia, 6, 91-115.

-Bernabéu Albert, S. (1992). Edificar en Desiertos. Los informes de fray Vicente de Mora sobre Baja California en 1777. México: Embajada de España.

-Del Río, Ignacio (2007). La adjudicación de las misiones de la Antigua California a los padres dominicos. En El noroeste del México colonial. Estudios históricos sobre Sonora, Sinaloa y Baja California. México: Instituto de Investigaciones Históricas-UNAM.

-Fernández Rodríguez, P. (1994). Los dominicos en la primera evangelización de México. Salamanca, España: Editorial San Esteban.

-González, M. del R. (1992). Las relaciones de la Iglesia y el Estado en México. En Estudios jurídicos en torno a la Constitución Mexicana de 1917 en su septuagésimo quinto aniversario. México: Instituto de Investigaciones Jurídicas-UNAM.

-Jedin, H. (1978). Manual de bistoria de la Iglesia (tt. II-VI). Barcelona: Editorial Herder.

-León-Portilla, M. (1983). La labor de los dominicos. En D. Piñera Ramírez (coord.). Panorama histórico de Baja California. Tijuana, Baja California: Centro de Investigaciones Históricas/Universidad Nacional Autónoma de México/Universidad Autónoma de Baja California.

-Martínez, P. L. (2005). Historia de Baja California. Mexicali, Baja California: Instituto de Investigaciones Históricas-Universidad Autónoma de Baja California.

-Meigs, P. (1994). La frontera misional dominica en Baja California. Mexicali, Baja California: Secretaría de Educación Pública/Universidad Autónoma de Baja California.

-Nieser, A. B. (1998). Las fundaciones misionales dominicas en Baja California, 1769-1822. Mexicali, Baja California: Universidad Autónoma de Baja California.

-Palou, F. (1792). Noticias de la Nueva California. México: Biblioteca Nacional de México.

-Porras Muñoz, G. (1980). El Patronato y el Vicepatrono. En Iglesia y Estado en Nueva Vizcaya, 1562-1821. México: Instituto de Investigaciones Jurídicas-UNAM.

-Rodríguez González, M. del C. (1999). Las relaciones Iglesia-Estado en España durante los siglos XVIII y XIX. Investigaciones Históricas. Época Moderna y Contemporánea, 19, 197-217, Universidad de Valladolid.

-Romero, M. J. (1971). Los dominicos en América Latina y el Caribe. Conferencia Interprovincial Dominicana de América Latina y el Caribe. Recuperado de http://cidalc.op.org/cidalc/ Historia.pdf.pdf

-Rouco Varela, A. M. (2008). Las relaciones Iglesia y Estado. Perspectivas actuales. Disertación del eminentísimo y reverendísimo señor cardenal obispo

\section{()(1) $(9$}


de Madrid en la Real Academia de Doctores de España. Madrid, España: Biblioteca Electrónica Cristiana. Recuperado de http://www.zenit.org/ es/articles/cardenal.rouco-varela-las-relacionesiglesia-y-estado.

\section{OTRAS FUENTES}

Archivos

AGN Archivo General de la Nación.

AHPLM Archivo Histórico Pablo L. Martínez, La Paz, Baja California Sur.

IIH-UABC Instituto de Investigaciones Históricas-Universidad Autónoma de Baja California. 